\title{
Bioluminescence-Sensing Assay for Microbial Growth Recognition
}

\author{
Heba Ramadan Eed, ${ }^{1}$ Nora S. Abdel-Kader, ${ }^{2}$ Mahmoud Helmy El Tahan, ${ }^{1}$ \\ Tianhong Dai, ${ }^{3}$ and Rehab Amin ${ }^{3,4}$ \\ ${ }^{1}$ Regional Center for Food and Feed (RCFF), Agricultural Research Center (ARC), Giza 12619, Egypt \\ ${ }^{2}$ Chemistry Department, Faculty of Science, Cairo University, Giza 12613, Egypt \\ ${ }^{3}$ Wellman Center for Photomedicine, Massachusetts General Hospital, Harvard Medical School, Boston, MA 02114, USA \\ ${ }^{4}$ National Institute of Laser Enhanced Sciences, Cairo University, Giza 12613, Egypt
}

Correspondence should be addressed to Rehab Amin; rehabamin@niles.edu.eg

Received 3 June 2015; Revised 9 August 2015; Accepted 23 August 2015

Academic Editor: Bambang Kuswandi

Copyright (C) 2016 Heba Ramadan Eed et al. This is an open access article distributed under the Creative Commons Attribution License, which permits unrestricted use, distribution, and reproduction in any medium, provided the original work is properly cited.

\begin{abstract}
The conventional methods for microbial viability quantification require cultivation and are laborious. There is consequently a widespread need for cultivation-free methods. The adenosine triphosphate (ATP) bioluminescence-sensing assay is considered an extremely effective biosensor; hence ATP is the energy currency of all living microbes and can be used as a rapid indicator of microbial viability. We developed an ATP bioluminescence-sensing assay to detect microbial viability. A bioluminescent recombinant E. coli strain was used with luciferase extracted from transformed bacteria. Results showed that there is a direct correlation between the bioluminescence intensity of the ATP bioluminescence-sensing assay and the microbial viability. Bacterial counts from food samples were detected using the developed sensing assay and validated by the traditional plate-counting method. Compared with the plate-counting method, ATP bioluminescence-sensing assay is a more rapid and efficient approach for detecting microbial viability.
\end{abstract}

\section{Introduction}

Outbreaks of food-borne illnesses caused by microbial pathogens are very common globally. Conventional approaches to the detection of food-borne pathogens rely heavily on fermentation tests, staining, and cell counting methods. There are many disadvantages of these methods, such as the complexity of the process and requirement for high skills and time. Therefore, there is an urgent need for the development of alternative approaches that could detect food-borne pathogens rapidly, accurately, and with high sensitivity [1].

Optical biosensors have recently been considered to be attractive alternatives to the existing conventional pathogen detection approaches [2]. Optical biosensors can sense the interaction of microbes with the analytes and correlate the observed optical signal to the concentration of the microbial population, based on measuring the photons that are involved in the process. Optical detection primarily includes the measurement of luminescence, fluorescence emissions, or absorbance [3].

Adenosine triphosphate (ATP) bioluminescence is considered to be an extremely effective biosensor, which provides a sensitive, nondestructive, and real-time assay [4-6].

The ATP bioluminescence-sensing assay relies on the fact that ATP is a major biological energy source existing in various microbes and, therefore, reflects the existence of living microbes [7].

Quantitative measurements of ATP bioluminescence have been applied to biological and environmental systems for years [8].

ATP bioluminescence creates a clearer picture by providing physiologically relevant data in response to a contaminant. Bioluminescence is quick and convenient to measure, resulting in real-time data. Whole-cell bioluminescent sensors have several advantages over traditional methods in that they are faster, less expensive, and less laborious. 
The aim of the current study is to develop a rapid, sensitive, and low-cost ATP bioluminescence-sensing approach to detect the presence or viability of food-borne bacteria.

\section{Materials and Methods}

2.1. Microbes, Chemicals, and Reagents. Escherichia coli XL1 blue supplemented with luciferase gene, which has been cloned into the NcoI/XhoI restriction sites of vector $\mathrm{pET} 28 \mathrm{~b}$ carrying kanamycin resistance, was kindly provided by Dr. Richard Weiss, staff member at Department of Molecular Biology, Salzburg University, Austria. Lactobacillus plantarum (American Type Culture Collection ATCC14917) was purchased from MERCIN, Faculty of Agriculture, Ain Shams University. Luria Broth (LB) and De Man, Rogosa, and Sharpe (MRS) media were purchased from Difco, France.

Luciferin, luciferase (EC 1.13.12.7), ethylenediaminetetraacetic acid disodium salt (EDTA $2 \mathrm{Na}$ ), magnesium acetate tetrahydrate, adenosine triphosphate (ATP), dithiothreitol (DTT), albumin bovine serum (BSA), tricine buffer, and hydroxymethyl aminomethane were purchased from Sigma Aldrich.

2.2. Transformation of Competent E. coli. E. coli cells were grown to log phase. Cells were then concentrated by centrifugation and resuspended in a solution containing calcium chloride. Plasmid DNA was mixed with the cells, and DNA presumably adheres to the cells. The mixture of DNA and cells was then heat shocked, which allowed the DNA to enter the cells efficiently. The cells were grown in nonselective medium to allow synthesis of plasmid-encoded antibiotic resistance proteins and then plated on antibiotic-containing medium (kanamycin) to allow identification of plasmid-containing colonies [9].

2.3. Standard Procedure for Measuring ATP. Standard ATP solutions were prepared in different concentrations ranging from 0.1 to $1 \mu \mathrm{M}$. Each concentration was prepared in 4 replicates in sterile, polystyrene, and flat-bottom 96-well tissue culture plate. Ten (10) $\mu \mathrm{L}$ suspensions from each concentration were exposed to $90 \mu \mathrm{L}$ of luciferin-luciferase reagent or working solution $(39 \mu \mathrm{g} / \mathrm{mL}$ luciferase, $78 \mu \mathrm{g} / \mathrm{mL}$ luciferin, $1.1 \mathrm{mmol} / \mathrm{L}$ EDTA $2 \mathrm{Na}, 11 \mathrm{mmol} / \mathrm{L}$ magnesium acetate tetrahydrate, $1.1 \mathrm{mg} / \mathrm{mL}$ BSA, $0.66 \mathrm{mmol} / \mathrm{L} \mathrm{DTT}$, and $25 \mathrm{mmol} / \mathrm{L}$ Tris-acetate, $\mathrm{pH}$ 7.8) [10]. The luminescence patterns and luminescence intensity were recorded after shaking by using FLx800 Microplate Reader (Biotech, USA) in the bottom-reading mode at $580 \mathrm{~nm}$.

2.4. Detection of Microbial Growth Using the Standard Procedure. L. plantarum were grown in MRS broth at $30^{\circ} \mathrm{C}$ for 24-48 $\mathrm{h}$ and shaken slightly for $1 \mathrm{~h}$. The bacterial suspensions were diluted to different bacterial concentrations ranging from $1.6 \times 10^{7}$ to $10^{8} \mathrm{CFU} / \mathrm{mL}$, which were confirmed by the conventional plate-counting method. Ten (10) $\mu \mathrm{L}$ bacterial suspensions from each concentration were exposed to $90 \mu \mathrm{L}$ of luciferin-luciferase working solution to obtain final concentrations ranged from $1.6 \times 10^{6}$ to $10^{7} \mathrm{CFU} / \mathrm{mL}$.
The bioluminescence of bacterial suspensions was immediately measured using the FLx800 Microplate Reader at $580 \mathrm{~nm}$, and luminescence intensity was recorded as Relative Light Unit (RLU).

2.5. Detection of ATP Using Transformed E. coli. The transformed E. coli were grown for $24 \mathrm{~h}$ with shaking in LB media at $37^{\circ} \mathrm{C}$. Bacterial suspension was standardized to an optical density value of 2.0 (about $1.6 \times 10^{9} \mathrm{CFU} / \mathrm{mL}$ ). The bacterial suspension was centrifuged and the supernatant was used as a source of luciferase. Standard ATP solutions were prepared in different concentrations ranged from 0.1 to $1 \mu \mathrm{M}$. Fifty (50) $\mu \mathrm{L}$ of each standard ATP concentration was added to $50 \mu \mathrm{L}$ of D-luciferin stock solution and $50 \mu \mathrm{L}$ bacterial luciferase extract. The bioluminescence of the reaction was immediately measured using the FLx800 Microplate Reader at $580 \mathrm{~nm}$ and luminescence intensity was recorded as RLU.

2.6. Detection of Microbial Growth Using Luciferase Extract of Transformed E. coli. L. plantarum suspensions were diluted to the same final concentrations ranging from $1.6 \times 10^{6}$ to $10^{7} \mathrm{CFU} / \mathrm{mL}$. Fifty (50) $\mu \mathrm{L}$ of each bacterial concentration was added to $50 \mu \mathrm{L}$ of D-luciferin stock solution and $50 \mu \mathrm{L}$ bacterial luciferase extract. The bioluminescence was immediately measured using the FLx800 Microplate Reader at $580 \mathrm{~nm}$.

2.7. Food Samples Screening. Two food samples from white cheese and protein concentrate (animal feed) were collected, diluted, and screened for bacterial growth using both traditional plate counting assay and the ATP bioluminescencesensing assay.

\section{Results and Discussion}

ATP bioluminescence-sensing assay is based on the fact that all living cells contain ATP. ATP is detected by using its reaction with luciferin and luciferase [8]. According to the mechanism of luciferin-luciferase reaction, light is emitted because the reaction forms oxyluciferin in an electronically excited state. The reaction releases a photon of light as oxyluciferin returns to the ground state [11].

The emission wavelength of the bioluminescence reaction was selected at $580 \mathrm{~nm}$; hence the reaction gives a strong peak emission at $580 \mathrm{~nm}[12,13]$. In the present study, ATP bioluminescence was produced by using the standard procedure adopting a standard ATP solution with a concentration of 0.1$1 \mu \mathrm{M}$. The correlation between bioluminescence intensity and ATP concentration $(\mu \mathrm{M})$ is shown in Figure $1(\mathrm{a})$. The bioluminescence intensity increases in a dose dependant manner with the ATP concentration [10]. Standard bioluminescence assay was applied to different cell densities of L. plantarum as a source of ATP.

In the present study, ultrasonic lysis of microbial cells was used as ATP extractants. The sonication technique is considered to be an effective method for the lysis and subsequent ATP extraction from microbial cells [14]. 


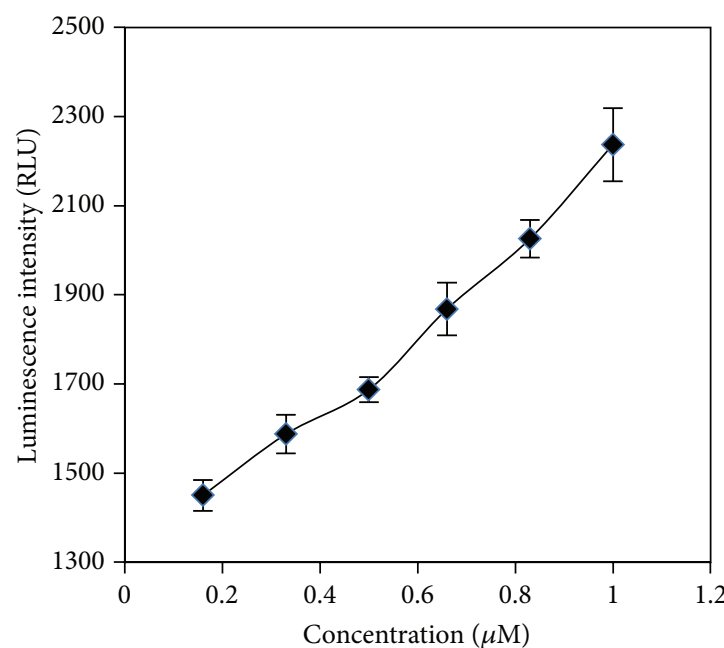

(a)

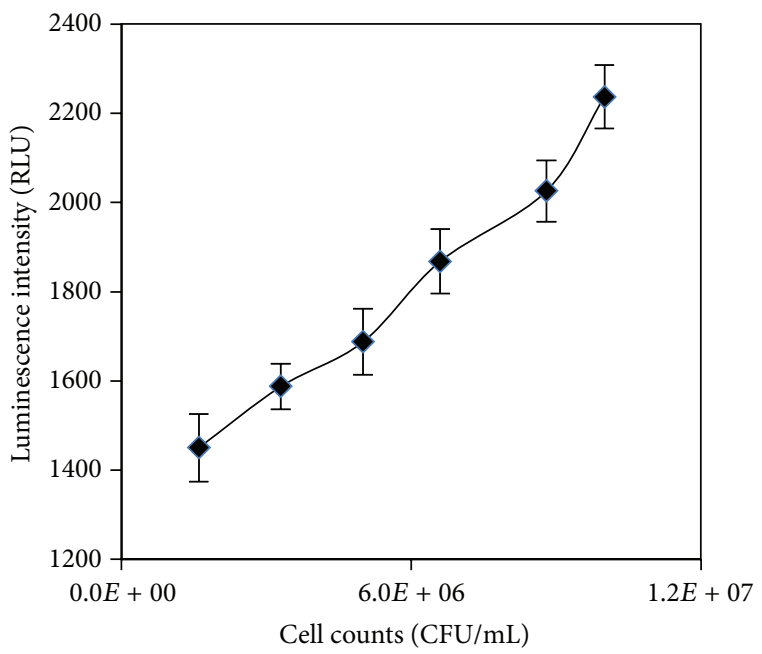

(b)

FIGURE 1: Luminescence (a) at different concentrations of standard ATP and (b) with increasing number of Lactobacillus plantarum species using standard luciferase working solution.



(a)

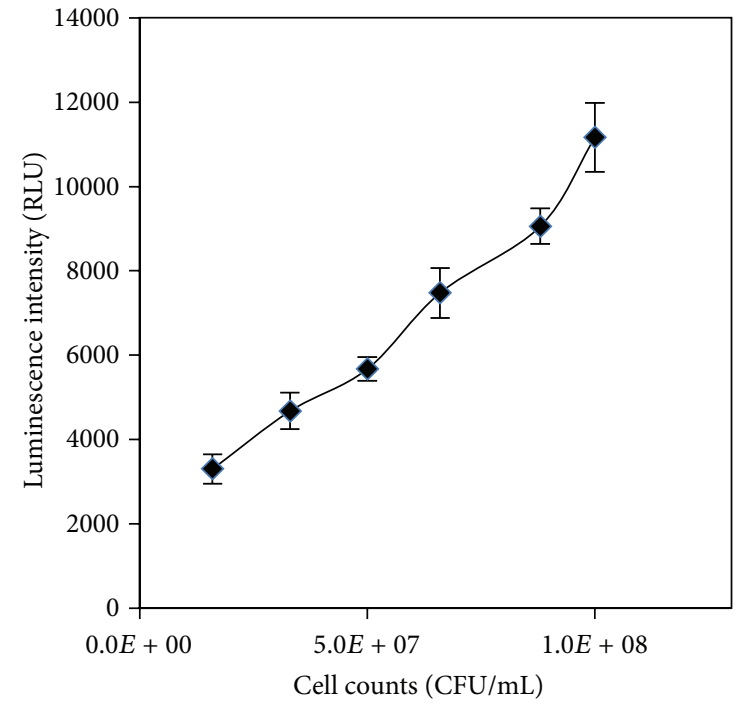

(b)

FIGURE 2: Luminescence (a) at different concentrations of standard ATP and (b) with increasing number of Lactobacillus plantarum species using bacterial luciferase extract from transformed $E$. coli.

Results showed a direct relationship between the bioluminescence intensity and the standard ATP concentrations (Figure 1(a)). There is also a direct relationship between the bioluminescence intensity and log colony count of $L$. plantarum (Figure 1(b)). It is observed that the bioluminescence intensity that resulted from $L$. plantarum was linearly proportional to the ATP concentrations.

Our results are in agreement with the previously reported studies that showed a good correlation between total bacterial counts and ATP concentrations in drinking water [15].

In the current study, E. coli used as a biosensor is typically produced with a constructed plasmid that codes for the luciferase enzyme. Result showed that the transformed E. coli can grow in media supplemented with kanamycin, while the nontransformed E. coli cannot. This indicates the positive uptake of the plasmid by E. coli.

Luciferase extracted from transformed bacteria was used instead of commercial luciferase. Results showed that there is a direct correlation between luminescence intensity and concentration of standard ATP (Figure 2(a)).

Meanwhile, there is a direct correlation between luminescence intensity of the developed bioluminescence-sensor and the CFU of L. plantarum (Figure 2(b)).

Food samples were screened for bacterial counts using the developed bioluminescence-sensing assay and the bacterial counts were validated by the traditional plate counting assay. 


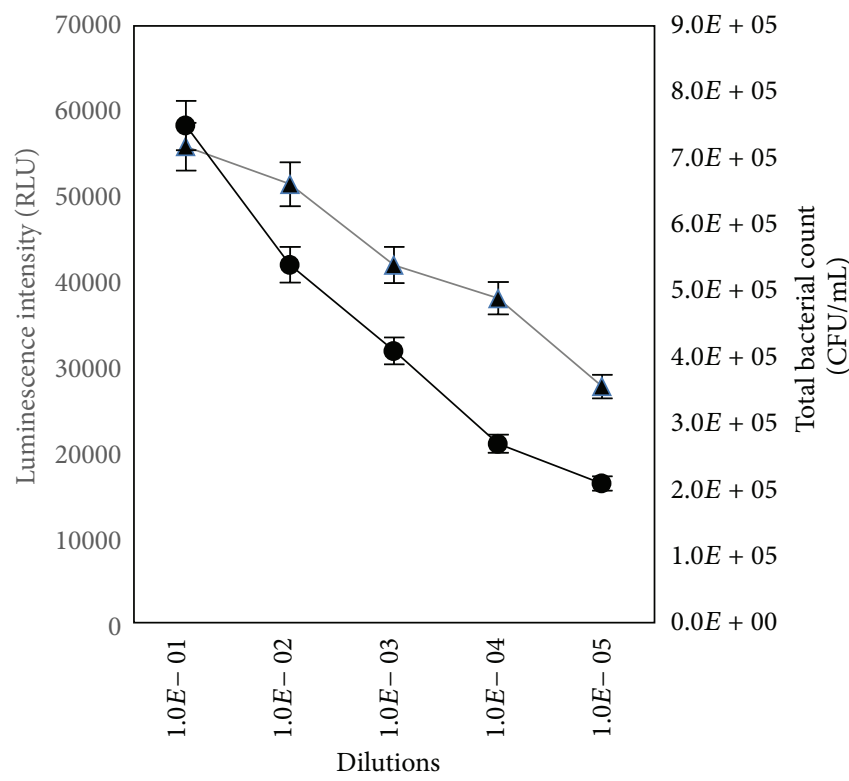

(a)



(c)

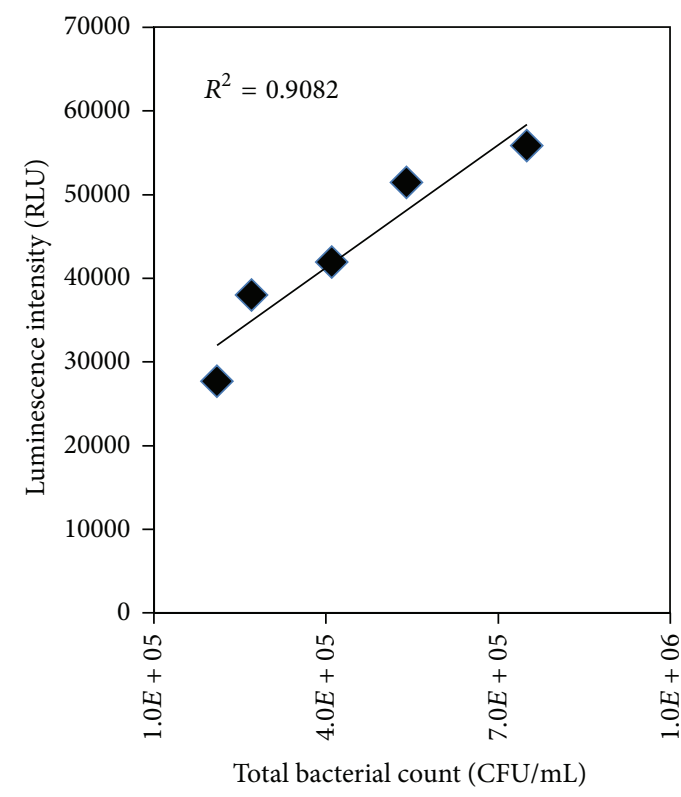

(b)

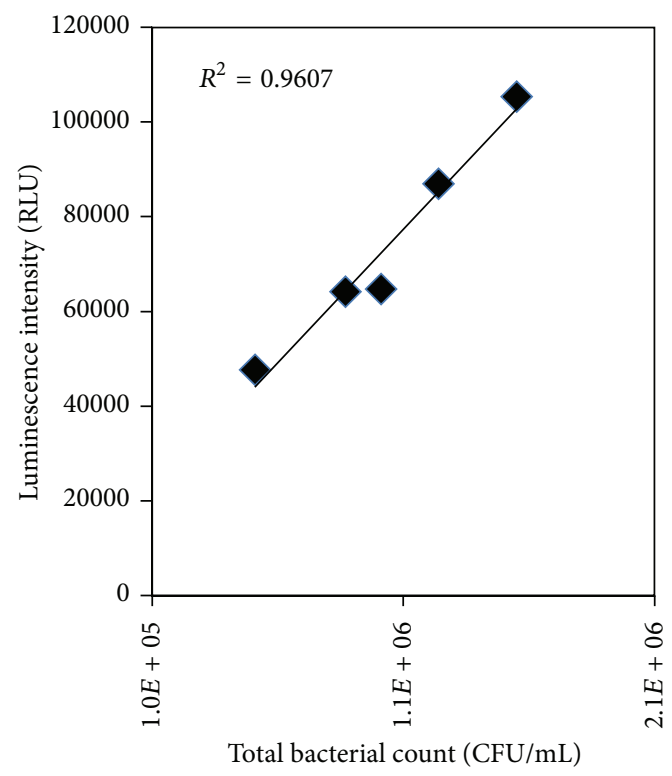

(d)

FIGURE 3: Relationship between bacterial count assay and the ATP bioluminescence assay performed for different dilutions of food samples. (a) Different dilutions of protein concentrate (animal feed) sample, (b) RLU versus CFU from protein concentrate sample, (c) different dilutions of white cheese sample, and (d) RLU versus CFU from white cheese sample, where RLU is Relative Light Units and CFU is Colony Forming Units.

Bioluminescence of the food samples reflects the total number of bacterial counts as shown in Figure 3. Results of protein concentrate sample (animal feed) were shown in Figures 3 (a) and 3(b), while the result of the white cheese sample was shown in Figures 3(c) and 3(d). Figures 3(a) and 3(c) demonstrated the correlation between the colony forming assay and the ATP bioluminescence-sensing assay performed for the two food samples. As can be seen from Figure 3,
ATP bioluminescence-sensor platform provides a similar approach of microbial viability quantification to the colony forming assay, whereas both assays indicate bacterial growth.

A direct relationship was observed between the bioluminescence intensity and the bacterial CFU as shown in Figures $3(\mathrm{~b})$ and 3(d). Compared with the plate counting assay, the detection time of the ATP bioluminescence-sensing assay is significantly reduced. The amount of bioluminescence 
produced is directly proportional to the total bacterial CFU in the food samples. A good linear correlation was obtained with the regression coefficient 0.908 for the protein concentrate sample and 0.960 for the white cheese sample.

ATP assay can be an excellent adjunct approach in nonspecific detection and quantification of bacteria in food products including milk and animal feed. Moreover, differentiation between live and dead cells can be achieved through bioluminescence assays.

In general, our study is a preliminary study toward developing a bioluminescent sensor for detection and identification of food-borne pathogens. For specific identification of pathogens, a combination of techniques is required to achieve desired sensitivity and specificity. Enzyme-linked immunosorbent assays (ELISA) are commonly used to rapidly detect food-borne pathogens, but both live and dead cells can elicit an antigenic response. Therefore, a combined ATP bioluminescence immunoassay would be of great interest for the detection of viable cells, while maintaining sensitivity and specificity [16]. Further studies should be done in the future to assess the combination effect on different pathogens.

\section{Conclusion}

Food-borne pathogens have always been a threat to public health, whereas the traditional detection approaches of microbial viability have many drawbacks. The implementation of the ATP bioluminescence-sensing assay is a reliable, rapid detection technique for monitoring the growth of foodborne pathogens. The ATP bioluminescence-sensing assay detects the bacterial viability quickly. Moreover, this method requires little to no sample pretreatment as compared to conventional approaches. In general, our research is a first step towards developing ATP bioluminescent assay as an excellent aid in nonspecific detection of bacterial contaminants.

\section{Conflict of Interests}

The authors declare that there is no conflict of interests regarding the publication of this paper.

\section{Acknowledgments}

This study was supported by a grant from the Center for Special Studies and Programs (CSSP), Bibliotheca Alexandrina. The authors would like to thank Dr. Richard Weiss, Professor at Department of Molecular Biology, Salzburg University, Austria, for providing them with the vector pET28b.

\section{References}

[1] R. Amin, "Nanotechnology in controlling infectious disease," in Nanomedicine in Health and Disease, V. R. P. R. J. Hunter, Ed., pp. 167-183, Science Publishers, New York, NY, USA, 2011.

[2] A. Singh, S. Poshtiban, and S. Evoy, "Recent advances in bacteriophage based biosensors for food-borne pathogen detection," Sensors, vol. 13, no. 2, pp. 1763-1786, 2013.
[3] T. D. Martins, A. C. C. Ribeiro, H. S. de Camargo, P. A. da Costa Filho, H. P. M. Cavalcante, and D. L. Dias, "New insights on optical biosensors: techniques, construction and application," in State of the Art in Biosensors-General Aspects, chapter 5, pp. 112-139, InTech, Rijeka, Croatia, 2013.

[4] P. Caputo, E. N. Ferri, S. Girotti, S. Gozzi, and P. Saracino, "Application of luminescent ATP rapid checks at ready-to-eat foods producing plant," Czech Journal of Food Sciences, vol. 29, no. 4, pp. 382-390, 2011.

[5] R. Chollet and S. Ribault, "Use of ATP bioluminescence for rapid detection and enumeration of contaminants: the milliflex rapid microbiology detection and enumeration system," in Bioluminescence-Recent Advances in Oceanic Measurements and Laboratory Applications, pp. 99-118, InTech, 2012.

[6] E. L. Larson, A. E. Aiello, C. Gomez-Duarte et al., "Bioluminescence ATP monitoring as a surrogate marker for microbial load on hands and surfaces in the home," Food Microbiology, vol. 20, no. 6, pp. 735-739, 2003.

[7] J. Luo, X. Liu, Q. Tian et al., "Disposable bioluminescence-based biosensor for detection of bacterial count in food," Analytical Biochemistry, vol. 394, no. 1, pp. 1-6, 2009.

[8] A. Caprita, "Applications of biochemiluminescence in quality assurance of food products," Agroalimentary Processes and Technologies, vol. 11, no. 1, pp. 161-172, 2005.

[9] J. Sambrook and D. W. Russell, Molecular Cloning: A Laboratory Manual, Cold Spring Harbor Laboratory Press, Cold Spring Harbor, NY, USA, 2001.

[10] B. He, X. Liu, W. Yue, A. Zhou, J. Luo, and X. Cai, "Rapid detection of bacteria without cultivation with a portable bioluminescence sensor system," African Journal of Microbiology Research, vol. 3, no. 9, pp. 575-580, 2009.

[11] T. O. Baldwin, "Firefly luciferase: the structure is known, but the mystery remains," Structure, vol. 4, no. 3, pp. 223-228, 1996.

[12] S. Zhou, S. Fushinobu, Y. Nakanishi, S.-W. Kim, T. Wakagi, and H. Shoun, "Cloning and characterization of two flavohemoglobins from Aspergillus oryzae," Biochemical and Biophysical Research Communications, vol. 381, no. 1, pp. 7-11, 2009.

[13] G. Reuter, T. Janvilisri, H. Venter, S. Shahi, L. Balakrishnan, and H. W. Van Veen, "The ATP binding cassette multidrug transporter LmrA and lipid transporter MsbA have overlapping substrate specificities," The Journal of Biological Chemistry, vol. 278, no. 37, pp. 35193-35198, 2003.

[14] K. A. Law, J. P. Derrick, and S. P. J. Higson, "Initial investigations into the ultrasonic lysis of microbial cells for the release of adenosine triphosphate," Analytical Biochemistry, vol. 317, no. 2, pp. 266-267, 2003.

[15] D. Trudil, L. Loomis, R. Pabon, J. A. K. Hasan, S. Garg, and C. L. Trudil, "Rapid ATP Method for the screening and identification of bacteria in food and water," Yeast, pp. 27-29, 2000.

[16] D. Lim and D. M. Hunter, "ATP-bioluminescence immunoassay," US Patent No. 8,518,658, US Patent and Trademark Office, Washington, DC, USA, 2013. 


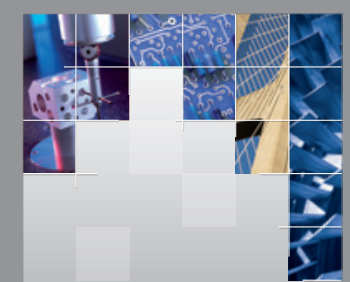

\section{Enfincering}
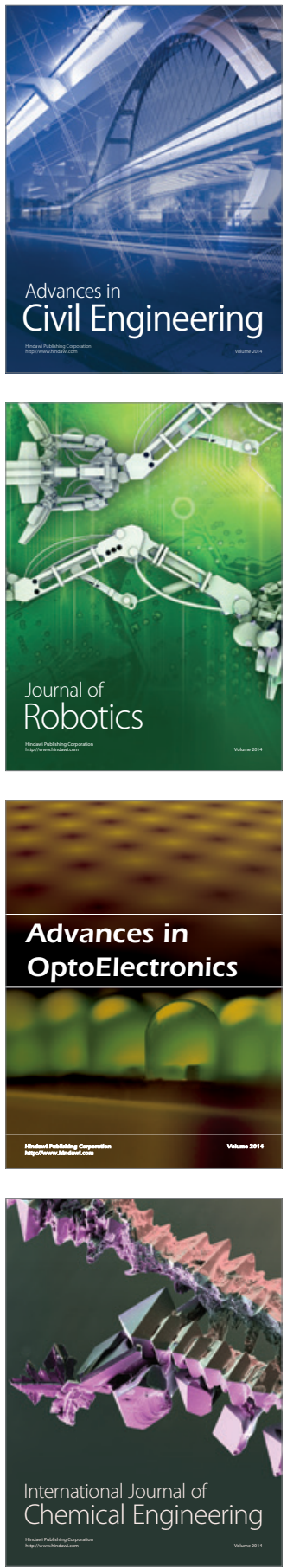

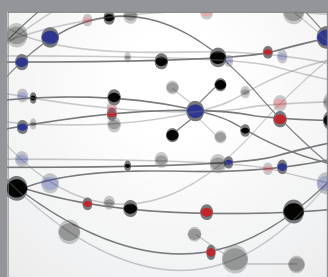

The Scientific World Journal

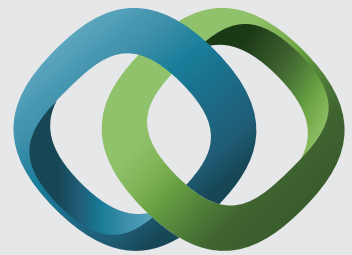

\section{Hindawi}

Submit your manuscripts at

http://www.hindawi.com
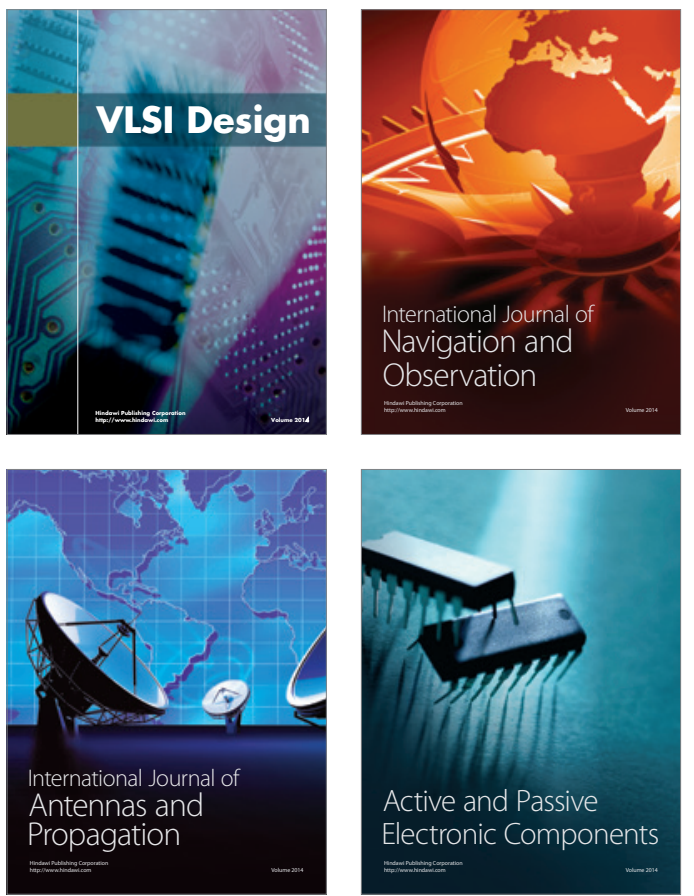
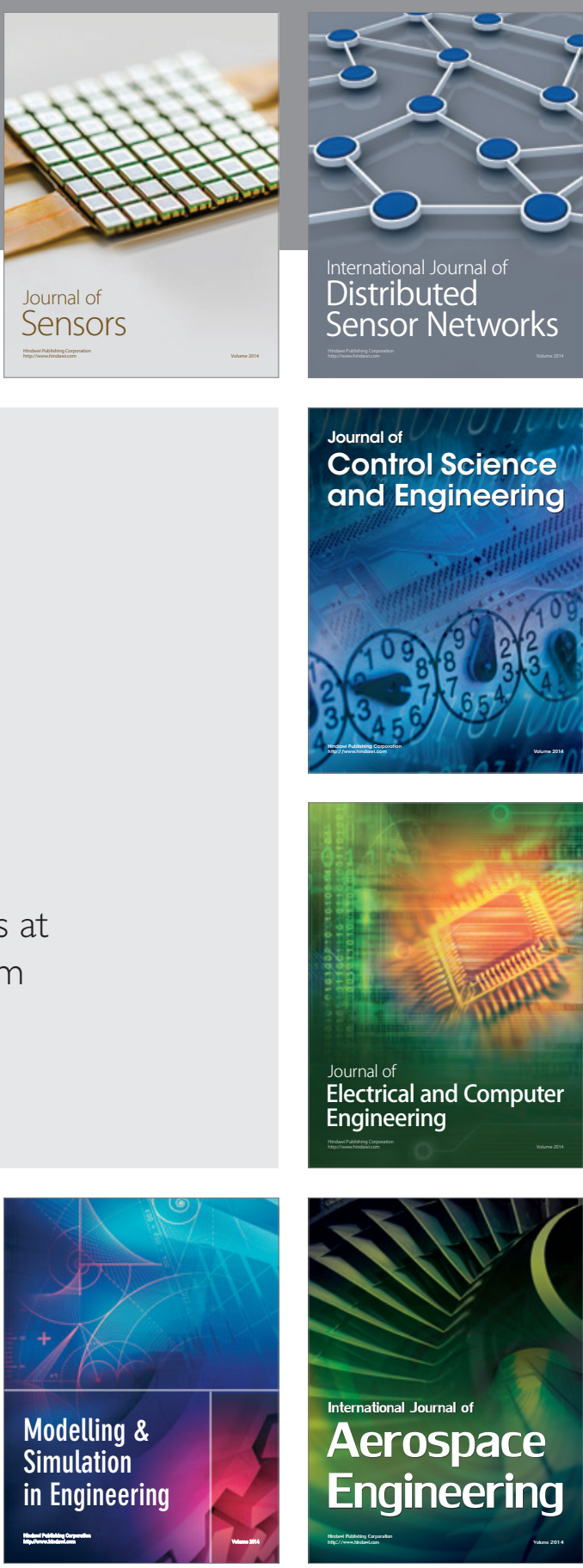

International Journal of

Distributed

Sensor Networks

Journal of

Control Science

and Engineering
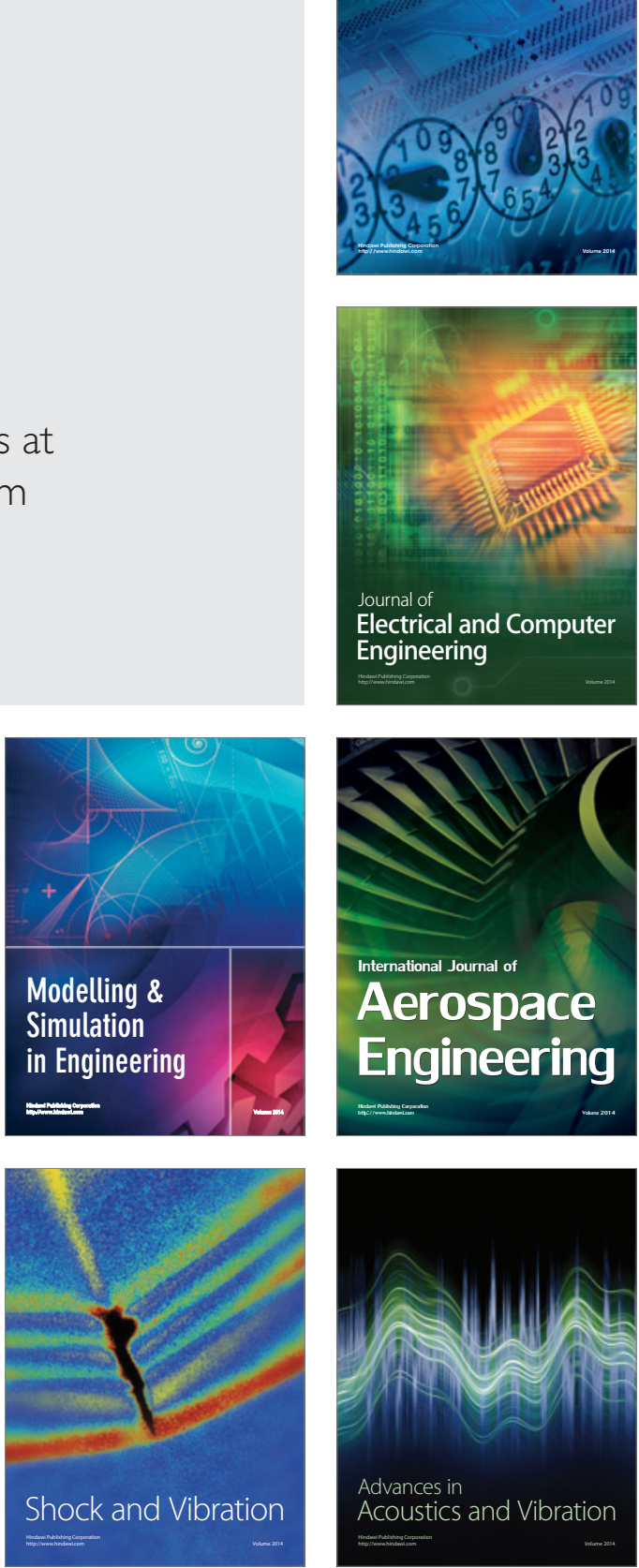